\title{
Millivolt Minute
}

National Cancer Institute

\section{Source}

National Cancer Institute. Millivolt Minute. NCI Thesaurus. Code C105512.

A SI derived unit of magnetic flux, equal to the flux that produces in a circuit of one turn an electromotive force of one millivolt, when the flux is uniformly reduced to zero within one minute. 